\title{
ASSESSMENT OF PSYCHIATRIC INFIRMITIES IN CANCER PATIENTS BY USING DASS21 IN A TERTIARY CARE HOSPITAL
}

\author{
Rachana Gade¹, Bala Shankar Ramavath², Goverdhan Puchhakayala³, Mounika Chiluka ${ }^{4}$
}

${ }_{1}^{1}$ Student, Department of Clinical Pharmacy, Vaagdevi College of Pharmacy, Warangal, Telangana, India.

${ }^{2}$ HOD, Department of Oncology, Kakatiya Medical College, Mahatma Gandhi Memorial Hospital, Warangal, Telangana, India.

${ }_{3}^{3}$ HOD, Department of Clinical Pharmacy, Vaagdevi College of Pharmacy, Kakatiya University, MGM Hospital, Warangal, Telangana, India.

${ }^{4}$ Associate Professor, Department of Clinical Pharmacy, Vaagdevi College of Pharmacy, Warangal, Telangana, India.

\section{ABSTRACT}

\section{BACKGROUND}

In India, around 2.0-2.5 million people are living with one (or) another type of cancer. Cancer leads to grief and pain. We wanted to evaluate the psychiatric infirmities (anxiety, depression and stress) in cancer patients using DASS 21.

\section{METHODS}

It is prospective and observational study, which was done at Department of Oncology, Mahatma Gandhi Memorial Hospital, Warangal. The data was gathered by administering the evaluated questionnaire response 21 - characteristics depression, anxiety and stress scale (DASS21) after taking informed consent and ethical approval.

\section{RESULTS}

112 subjects satisfying the inclusion and exclusion criteria were included in the study. The mean age of the cancer patients is $(53.3 \pm 10.97)$ years with the most frequent age group being $(30-39)$ years with female preponderance $(80 \%)$. The internal consistency of DASS is (0.75). No significant correlation was found between age and psychiatric infirmities. There is a significant correlation found between depression and anxiety $(\mathrm{p}<0.0005)$, stress and depression $(\mathrm{p}<0.0004)$, stress and anxiety ( $<<$ $0.0001)$, anxiety and depression $(\mathrm{p}<0.0001)$. Breast cancer has the highest prevalence of anxiety and depression.

\section{CONCLUSIONS}

Prevalence of anxiety is more when compared to depression and stress. The patients who are on radiation therapy are more liable to show psychological disorders. Breast cancer, head and neck cancer have higher prevalence of psychiatric disturbances in our study.

\section{KEY WORDS}

Cancer, DASS21, Depression, Anxiety, Stress

HOW TO CITE THIS ARTICLE: Gade R, Ramavath BS, Puchhakayala G, et al. Assessment of psychiatric infirmities in cancer patients by using DASS21 in a tertiary care hospital. J. Evolution Med. Dent. Sci. 2019;8(27):2153-2156, DOI: 10.14260/jemds/2019/472

\section{BACKGROUND}

The uninhibited proliferation of atypical cells is termed as cancer. These unusual cells are termed as cancer cells (or) tumour cells.(1) Malignancy is a significant cause of death worldwide. India is no exception to this.(2)

In India, around 2.0-2.5 million people are living with one (or) another type of cancer; over and above 7-8 lakh new cases are added every year.(3) Cancer leads to psychological stress. A mortal ailment like cancer will doubtlessly have pathetic repercussions.

The occurrence of cancer has been affiliated with elevated measure of psychological stress. The association between dysphoric effect and cancer has been reported by Galen long ago. Ethereally these are disorders with emotional and

'Financial or Other Competing Interest': None.

Submission 08-04-2019, Peer Review 22-06-2019,

Acceptance 28-06-2019, Published 08-07-2019.

Corresponding Author:

Dr. Goverdhan Puchhakayala,

Professor and HOD,

Department of Clinical Pharmacy,

Vaagdevi College of Pharmacy,

Kakatiya University, MGM Hospital,

Warangal-506002, Telangana, India.

E-mail: goverdhanpuchakayala21@gmail.com

DOI: $10.14260 /$ jemds $/ 2019 / 472$

\section{(c) (i) $९$}

behavioural symptoms which are the causes to a recognisable stressor. A panic illness like cancer will compulsorily have emotional outcomes. In order to cure the condition systematically, it is necessary to acquire perception into the prevalence, severity, direction of the psychological abnormality and the factors affecting them.(2) Cancer sufferers must face assorted strain and elements which cause their psychosomatic anguish, principally apprehension and melancholy.(4) These may affect the outwear of the patients significance in standard of living, making appropriate treatment decisions; acquiesce with treatment and patients comfort.(5) More than half of psychological distresses experienced are adjustment disorders accompanied by delirium, major depression, depression and/or anxiety. Further (Predominantly anxiety disorders, major depressive disorders and behaviour disorders) are foregoing situation frequently are aggravated by the illness.(3)

In spite of recent advance in securing revocation and possible cancer cure, it still remains a disease which is connected with hopelessness, pain, fear and death. Its diagnosis and treatment often produce psychological stress resulting from veritable. Cancer induces psychological trait that becomes a mark for grief and pain that is the reason why psychosocial oncology research studies indicated that a noteworthy percentage of cancer patients at all stages of the 
sickness has been oppress with psychological suffering.(2) However the psychological distress has the chances of interrupting the patient's quality of life and also influencing their option of treatments for cancer.(4) Internationally regimen of screening for distress is proposed as the compulsory standard for the good cancer care. The highest occurrence of depression is seen in the patients who are in the advance stages of their respective diagnosed neoplasm, decreased physical activity and also subjects with severe illness. However, patients who are diagnosed with cancer are frequently having high percentage of correlation was detected in between depression and anxiety. (5)

The incident of some psychiatric sickness is elevated in patients undergoing radiation therapy (or) palliative treatment, terminally-ill patients, and sufferer experiencing irrepressible pain, which also involve an increased threat for suicidal and disorder psychological bearing.(6) Some studies foresee that the approximately $20-50 \%$ of cancer victims need a psychiatrist for treating major depression (or) anxiety throughout their cancer experience.(6,7) Adverse impact on quality of life, causing of nausea and vomiting, hindering with sleep habits and feelings of pain are escalated by anxiety associated with cancer. All cancer patients are influenced by cancer- related stress and which deleteriously impacts cancer consequence in terms of response to therapy, disease progression, quality of life and survival. In this contemporary time; a significant number of guidance programs, literature and research have been progressed with comprehensive towards to internment of psychological issues. Familiarity between psychological and physiological domains of cancer risk and survival are being explored vigorously through psychoneuroimmunology. Research in the zone of advancement of psychological knowing of disease procedure was given least attention. Psycho-oncology has steadily become the juvenile subspecialty of oncology.(3) The exact evaluation of the prevalence of adjustment disorders and various psychiatric illnesses is highly dominant in designing the management programmes.(2)

With the above said pondering, the primary objective of the present study was to approximate the depression, anxiety and stress levels in surviving cancer patients. The secondary objective was to correlate the primary objective with different age group, gender and cancer types. The greatest quantity of questionnaires and rating scales which are used in the psychological screening are hard to analyse exactly because they may also contain somatic symptoms that can be referable to either the medical or psychiatric conditions. (5)

In this present study, we have planned a validated selfreported, response-based questionnaire using 21-item Depression Anxiety Stress Scale (DASS21) which is designed to measure the severity of a range of symptoms and it can be very simply finished in the hospital waiting room. Screening will be done to the patients for those who visit the hospital and also for them those who are staying in the hospital.

\section{METHODS}

This study is a prospective, Observational study which was carried out at Oncology, Department of a tertiary care hospital, Mahatma Gandhi Memorial Hospital, Warangal.

A total of 112 study subjects were evaluated for DAS based on the following inclusion and exclusion criteria before initiation of the study: 1 . Both males and females of any age groups, 2. Patients who are diagnosed with cancer, 3. Patients who are taking different cancer therapies like chemotherapy, radiation therapy, surgery and combination therapy, 4 . No known mental problems (or) being treated with psychotropic drugs. Exclusion criteria include 1. The Patients with past history of Psychiatric disorders, 2. Pregnant and lactating women, 3. Patients who are on antipsychotic therapy. An approval was taken from the Institutional Review Board, Ethics Committee (Approval NO MGM/VCOP/PHARMD/V/14/2018) and written informed consent was obtained from all patients before participation. A set configuration of questionnaire accommodating demographic and psychological questions (DASS- 21) has been imparted to the cancer patients and it is provided accordingly to the subject's understandable language or their local language. The answer to the survey form was gathered from the patients who are from outpatient department as well as inpatient department and they who are undergoing their respective treatment like chemotherapy, radiation therapy sessions. Characteristic features like sex, age, educational status, occupation, marital status, address and particulars of family history; cycles of radiation therapy, chemotherapy as well as extent of diagnosis, symptoms, level of income was also assembled. This data was collected from patients who have been diagnosed with different types of cancer like breast, colorectal, stomach, oesophagus, lung, thyroid cancer, cervix, ovarian, head and neck, brain, colon, rectal, endometrial cancer programmed for surgery, radiation therapy, chemotherapy and combination therapy.

\section{Tools Used}

The DASS-21 is a 21-item self- report questionnaire designed to measure the severity of a range of symptoms common to DAS. It is a generic scale that shows strong internal consistency and reliability for each subscale (DAS) and it has been corroboration in cancer patients.

In completing the DASS, the individual is required to indicate the presence of symptom over the previous week. Each item is scored from 0 to 3 . There are four possible responses in terms of severity of frequency, organized in scale from 0 to 3 . The result is obtained by adding of the scores of the items.

The depressions subscale assesses symptoms like inertia; anhedonia; dysphoria; lack of interest/involvement; devaluation of life and discouragement. The anxiety subscale evaluates excitation of the autonomous nervous system; musculoskeletal effects; situational anxiety and subjective anxiety occurrence. Finally, the stress subscale assesses difficulty to relax; nervous excitation; easy perturbation/agitation; irritability/exaggerated reaction and impatience. Higher score corresponds to more severe psychological disorder that is reflected in critical functioning of the DASS is to assess the severity of core symptoms of DASS. $(8)$

\begin{tabular}{|c|c|c|c|}
\hline Psychological Properties & Male & Female & Total \\
\hline Depression observed & $2(1.8 \%)$ & $6(5.3 \%)$ & $7.1 \%$ \\
\hline Depression not observed & $20(17 \%)$ & $84(75 \%)$ & $92 \%$ \\
\hline Anxiety observed & $14(12.5 \%)$ & $62(55.3 \%)$ & $67.8 \%$ \\
\hline Anxiety not observed & $8(7.1 \%)$ & $28(25 \%)$ & $32.1 \%$ \\
\hline Stress observed & $6(5.4 \%)$ & $14(12.5 \%)$ & $17.9 \%$ \\
\hline Stress not observed & $16(14.3 \%)$ & $76(67.8 \%)$ & $82.1 \%$ \\
\hline Table 1. Gender Wise Categorization of Cancer Patients with \\
Psychiatric Infirmities \\
\hline
\end{tabular}



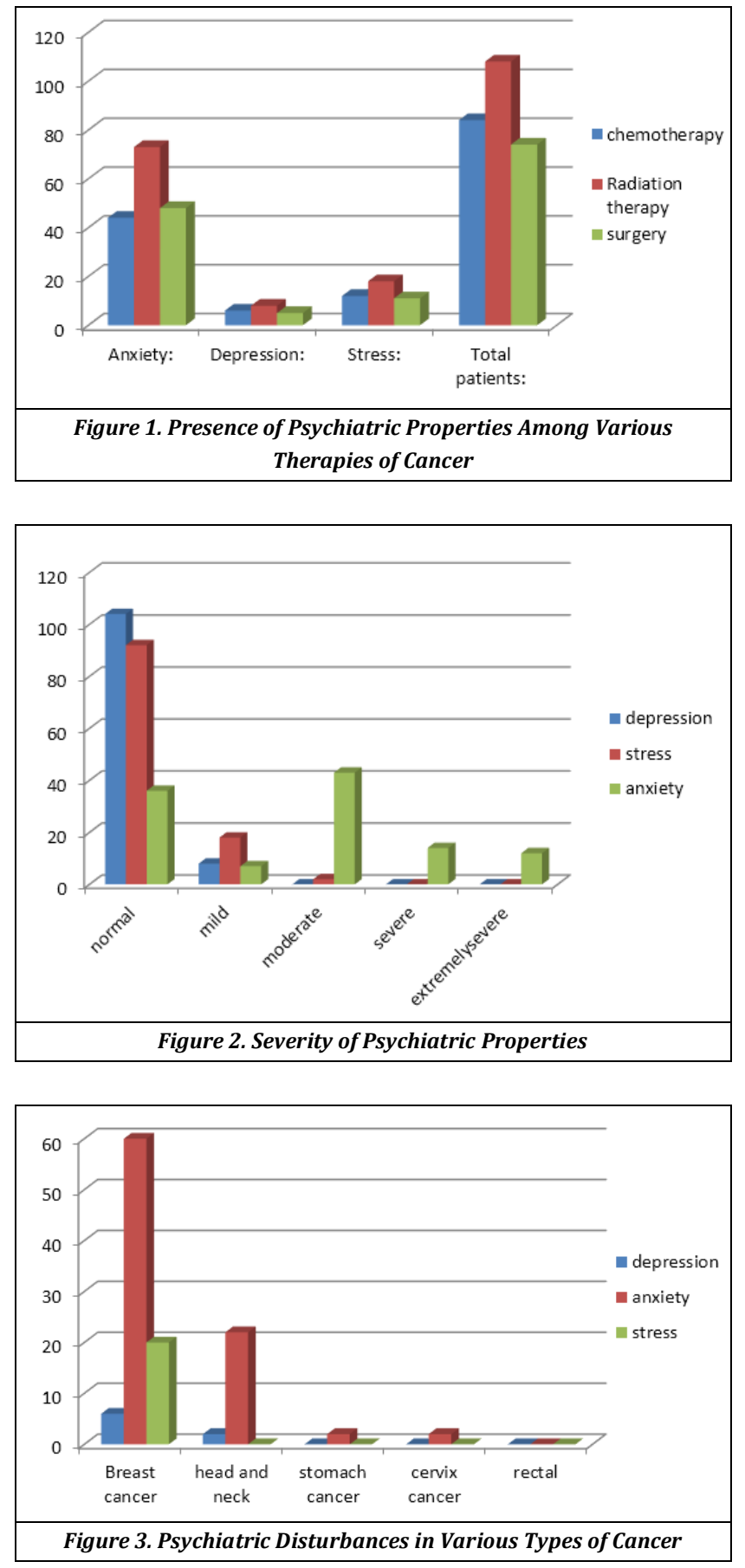

\section{Statistical Analysis}

The data is collected and analysed by Microsoft office excel version (2007) and graph pad prism (7.01). Frequency, mean, percentages and standard deviation were deliberated as per the necessity of the study. Pearson's correlation test was performed to find out the relationship between age and DAS. Cronbach alpha is to measure internal consistency. All $\mathrm{p} \leq$ 0.05 are considered as significant.

\section{RESULTS}

All eligible 112 subjects participated in the study and the mean age of the cancer patients are $(53.3 \pm 10.97)$ years with most common age group being (50-59) years with female predominance $80 \%$ out of the total subjects, the least number of patients were seen in the age group of (30-39) years with only $7 \%$. $14 \%$ were literate and $86 \%$ were illiterate. Out of our 112 cancer victims Stomach cancer 3.5\%, Breast cancer
66.07\%, Rectal cancer 1.7\%, Head and Neck cancer $26.78 \%$ and Cervix cancer $1.78 \%$. Distributions of clinical variables shows that $28.5 \%$ were smokers and alcoholics were $33.9 \%$. The reliability (internal consistency) of DASS 21 total score were estimated using Cronbach's alpha. Alpha was 0.75 .

Gender wise, females were more prone to depression $7 \%$, anxiety $76 \%$ and stress $14 \%$ than males. There was no significant correlation between Age and Psychiatric disturbances. Whereas R- squared value is 0.01303 for age and stress. R- Squared value for age and depression was found by 0.005032 and R-squared for anxiety and age was 0.01154 .

Details of psychiatric infirmities gender wise are shown in [Table-1].

Patients were undergoing various treatments for cancer which includes Radiation therapy 108 (96.4\%), Chemotherapy 84 (75\%), Surgery 74 (66.07\%) and combination therapy of chemotherapy and radiation therapy $80(71.4 \%)$ and presence of psychiatric properties among people taking various therapies is exhibited in [Figure-1].

The mean score of depression in cancer patients was 3.53(ST.D \pm 3.08 ), mean score of stress is 11.57 (ST.D \pm 3.65 ) and mean score of anxiety found to be 10.64(ST.D \pm 6.32 ). Severity of psychiatric infirmities was shown in [Figure-2]. Regional distribution shows that individuals from rural area are $74(66 \%)$ and from urban area are $38(34 \%)$. People in rural area are more prone to stress (22\%) than urban region (16\%).Psychological disturbances among different types of cancer were manifested in [Figure-3].

The correlation is found between anxiety and depression $(\mathrm{p}<0.0005)$, Where R-squared value is 0.1063 . Stress and depression $(\mathrm{p}<0.0004)$, Whose $\mathrm{R}$ - squared value is 0.1072 . Anxiety and stress $(\mathrm{p}<0.0001)$ and $\mathrm{R}$ - squared value is 0.4661 . Anxiety and depression $(\mathrm{p}<0.0001)$, R- squared value is 0.5856 .

\section{DISCUSSION}

In this study of 112 patients admitted in oncology ward among them males were $22(20 \%)$ and females were $90(80 \%)$ which was juxtapose to John et al,(9) who reported that the general adult population was females $50 \%$, males $45.5 \%$. The outcome of our study revealed that the mean age of the sample was $(53.3 \pm 10.971)$ years with a range of (30-39) years, which was contrasting to the work done by John et. al,(9) who reported mean age was $(40.9 \pm 15.9)$ years with range of (15-91) years. The percentages of participants in each of 5 age bands (30-39, 40-49, 50-59, 60-69, 70-79) was $7 \%, 27 \%, 32 \%, 25 \%, 9 \%$ which was contrasting to the work done by John et. al $(9)$ who reported that in each of four bands (18-29, 30-44, 45-59, 60+) was 30\%, 31\%, 26\% and 14\%.

The presence of depression, anxiety among people in urban area was $4(10 \%)$ and $29(74 \%)$ respectively. People in rural area the existence of depression was $4(6 \%)$ and anxiety was $45(72 \%)$, which was not consistent with the study done by Abdhul Rahman et al(10) reported that depression 61 (56.4\%), anxiety 39 (9.59\%) among people who are from urban area and from rural area depression was 52 (10.4\%) and anxiety $50(10 \%)$. Regarding educational levels people who are below diploma level were $16(14 \%)$ and 96 (86\%) were illiterate which was opposite to the study performed by Novin et al(11) reported that below diploma were $35.3 \%$ and illiterate were $35.3 \%$. The presence of depression among 
educated people were $2(13 \%)$, anxiety $66(56 \%)$, stress 15 (13\%).

The history of chemotherapy has been shown to be associated with psychiatric problems. The present study has shown that depression was $10 \%$ and anxiety was $71 \%$ for people who are on chemotherapy which was colligate to the study done by Pandey et al.(12) The potentiality of depression and anxiety among people who are on radiation therapy was $8 \%, 74 \%$ respectively, which was complementary to the study conducted by Schmale et al.(13)

Surgical treatment has been associated with psychiatric problems $75 \%$ prevalence of anxiety and $8 \%$ depression which was at variance with work done by Gopalan et al. Stress levels among males were $6 \%$ and females were $17 \%$ which was juxtapose to the research done by Harminder et al.

The prevalence of depression in females was $7 \%$ and anxiety was $76 \%$ and in male's depression was $9 \%$ and anxiety was $64 \%$ which was not complimentary to the results of study conducted by Harminder et. al.(15)

Breast cancer, Head and Neck cancer has the highest prevalence of anxiety and depression in our study and there was no significant relationship between depression and anxiety with age which was dissimilar to Novin et. al(11) study.

\section{CONCLUSIONS}

Psychological conditions like depression, anxiety and stress are more prevalent in chronic medical conditions like cancer. Our results state that the prevalence of anxiety is more when compared to depression and stress. Patients who are on radiation therapy are more liable to show psychological disorders. In our study, there is a significant correlation between anxiety, depression and stress. Breast cancer, head and neck cancer have higher prevalence of psychiatric disturbances in our study and there was no significant correlation between age and psychiatric parameters. Accordingly, there should be a close collaboration between oncologists and mental health professionals to improve patient outcomes like medication adherence and quality of life. Further studies include Impact of providing patient counselling and better treatment options for the people who are diagnosed with psychiatric illness, which may help in maintaining good quality of life.

\section{ACKNOWLEDGEMENT}

I profoundly thank my clinical guide Dr. Bala Shankar and Dr. Goverdhan Puchhakayala for their support and constant motivation.

\section{REFERENCES}

[1] Burnet M. Cancer - a biological approach: I. The processes of control. II. The significance of somatic mutation. British Medical Journal 1957;1(5022):77986.

[2] Gopalan MR, Karunakaran V, Prabhakaran A, et al. Prevalence of psychiatric morbidity among cancer patients-hospital-based, cross-sectional survey. Indian Journal of Psychiatry 2016;58(3):275-80.

[3] Singh RP, Singh H, Singh CJ, et al. Screening of psychological distress in cancer patients during chemotherapy: a cross-sectional study. Indian Journal of Palliative Care 2015;21(3):305-10.

[4] Kugaya A, Akechi T, Okuyama T, et al. Screening for psychological distress in Japanese cancer patients. Japanese Journal of Clinical Oncology 1998;28(5):3338.

[5] Carroll BT, Kathol RG, Noyes R Jr, et al. Screening for depression and anxiety in cancer patients using the Hospital Anxiety and Depression Scale. General Hospital Psychiatry 1993;15(2):69-74.

[6] Chochinov HM. Depression in cancer patients. The Lancet Oncology 2001;2(8):499-505.

[7] Carlson LE, Bultz BD. Benefits of psychosocial oncology care: improved quality of life and medical cost offset. Health and Quality of Life Outcomes 2003;1:8.

[8] Lovibond SH, Lovibond PF. Manual for the Depression Anxiety Stress Scales. Available from Room 1005 Mathews Building, University of New South Wales, NSW 2052, Australia. 2nd edn. Sydney: The Psychology Foundation 1995.

[9] Crawford JR, Henry JD. The Depression Anxiety Stress Scales (DASS): normative data and latent structure in a large non-clinical sample. British Journal of Clinical Psychology 2003;42(Pt 2):111-31.

[10] Al Atram AR. Prevalence of psychiatric disorders in a sample of elderly residents in rural and urban population of Zulfi Region-Saudi Arabia. Journal of Psychology \& Psychotherapy 2015;5(1):1.

[11] Nikbakhsh N, Moudi S, Abbasian S, et al. Prevalence of depression and anxiety among cancer patients. Caspian Journal of Internal Medicine 2014;5(3):16770.

[12] Pandey M, Sarita GP, Devi N, et al. Distress, anxiety, and depression in cancer patients undergoing chemotherapy. World Journal of Surgical Oncology 2006;4(1):68.

[13] Schmale AH, Morrow GR, Davis A, et al. Pre-treatment behavioral profiles associated with subsequent psychosocial adjustment in radiation therapy patients: a prospective study. The International Journal of Psychiatry in Medicine 1983;12(3):187-95. 